\title{
Mabrouck Rachedi, Le Poids d'une âme
}

\section{Ilaria Vitali}

\section{(2) OpenEdition}

\section{Journals}

\section{Edizione digitale}

URL: http://journals.openedition.org/studifrancesi/9058

DOI: 10.4000/studifrancesi.9058

ISSN: 2421-5856

\section{Editore}

Rosenberg \& Sellier

\section{Edizione cartacea}

Data di pubblicazione: 1 octobre 2008

Paginazione: 499

ISSN: 0039-2944

\section{Notizia bibliografica digitale}

Ilaria Vitali, «Mabrouck Rachedi, Le Poids d'une âme», Studi Francesi [Online], 155 (LII | II) | 2008, online dal 30 novembre 2015, consultato il 09 janvier 2021. URL: http://journals.openedition.org/ studifrancesi/9058 ; DOI: https://doi.org/10.4000/studifrancesi.9058

Questo documento è stato generato automaticamente il 9 janvier 2021.

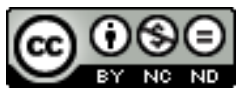

Studi Francesi è distribuita con Licenza Creative Commons Attribuzione - Non commerciale - Non opere derivate 4.0 Internazionale. 


\title{
Mabrouck Rachedi, Le Poids d'une âme
}

\author{
Ilaria Vitali
}

\section{NOTIZIA}

MABROUCK RACHEDI, Le Poids d'une âme, Paris, Lattès, 2006, pp. 214.

1 Nato nel 1976, Mabrouck Rachedi ha lavorato come analista finanziario, prima di lasciare tutto per dedicarsi alla scrittura. Con l'obiettivo di dar voce alle realtà periferiche della Francia contemporanea, nel 2007, insieme ad altri giovani scrittori di banlieue, ha fondato il collettivo "Qui fait la France?". Oltre a due novelle edite nella prima raccolta del collettivo, Chroniques d'une société annoncée (Stock, 2007), Rachedi ha recentemente pubblicato il saggio Éloge du miséreux (Michalon, 2007), autentico manuale di sopravvivenza che svela «l'art de vivre avec rien du tout». Amante di Stendhal e Dostoevskij, Mabrouck Rachedi è soprattutto l'autore di Le Poids d'une âme, un romanzo profetico, che preannunciava l'esplosione delle émeutes nelle banlieue parigine.

2 Il romanzo incomincia in una giornata come tante. Alle otto del mattino, il diciottenne Lounès si prepara per andare a scuola e non sa ancora che qualche ora dopo finirà in carcere, accusato a torto di essere un terrorista. Una serie di micro-eventi che, isolati gli uni dagli altri, sarebbero senza conseguenze, innesca una bomba ad orologeria. Dopo essere stato espulso da scuola solo perché ha perso l'autobus ed è arrivato qualche minuto in ritardo, Lounès vaga per la banlieue parigina. Per evitare di farsi vedere dai fratelli, cambia quartiere e finisce per incontrare due amici che stanno andando a casa di un pusher. Di malavoglia, il ragazzo li segue nell'appartamento, dove pochi minuti dopo interviene la polizia e li arresta. In carcere, i due "amici" non si fanno scrupolo a dare a lui la colpa, incollandogli addosso l'etichetta di trafficante di droga e di armi.

3 Nel frattempo, nella banlieue scoppia una guerra senza confine tra ragazzi e polizia. Mentre le macchine bruciano, Lounès si trova al posto sbagliato nel momento sbagliato e finisce per diventare il capro espiatorio ideale. I giornalisti ingigantiscono la notizia 
del suo arresto: da diciottenne senza voti brillanti a scuola, Lounès diventa capo di una rete terroristica internazionale. «Lounès n'a pas de casier judiciaire? Une preuve de sa ruse. Il s'agite? Son corps le trahit. Il se tait, las de répondre aux mêmes questions? La stratégie du silence confond le parfait coupable» (p.71). Fortunatamente, la serie di eventi sventurati che ha portato il ragazzo in carcere sembra capovolgersi di colpo: tutte le persone che hanno contribuito, anche solo involontariamente, alla sua incarcerazione, tentano di aiutarlo. La banlieue intera incomincia a mobilitarsi per lui, mostrando il suo lato più umano.

4 Parallelamente alle vicende del giovane Lounès, Rachedi racconta la storia di Gilles Tourlier, il più grande cordaio di Francia dopo la seconda guerra mondiale, e descrive in dettaglio il percorso di una corda difettosa. Dopo essere passata di mano in mano, sarà quella stessa corda a capitare tra le dita del ragazzo in carcere. Ignorando che tutti si stanno mobilitando per lui e temendo il peggio, il ragazzo decide di impiccarsi, ma la corda di Tourlier cederà al momento opportuno, salvandolo dalla morte. Ed è proprio all'ultima riga che il lettore coglie il senso profondo del titolo: "l'âme" in questione è il cuore della corda, «la partie qui assure l'élasticité et absorbe l'énergie du choc en cas de chute» (p. 188). Quel vizio di fabbricazione avrà un peso fondamentale nella vita di Lounès, a dirci che anche le cose in apparenza banali possono avere grande importanza nella vita.

Un romanzo che non è solo il racconto esplosivo di una banlieue alla deriva, ma anche una riflessione profonda sul caso, sulle coincidenze e sul valore di ogni singolo atto compiuto. 